\title{
OUR EXPERIENCE WITH ATOPY PATCH TESTS WITH AEROALLERGENS
}

\author{
Jarmila Čelakovská1, Květuše Ettlerová2, Karel Ettler'1, Jaroslava Vaněčkovál
}

Charles University in Prague, Faculty of Medicine and University Hospital Hradec Králové, Czech Republic: Department of Dermatology and Venereology ${ }^{1}$, Department of Allergy and Clinical Immunology, Outpatient Clinic, Hradec Králové, Czech Republic ${ }^{2}$

Summary: Aim of our study was to evaluate the importance of atopy patch testing with aeroallergens as a diagnostic method in patients suffering from atopic dermatitis. Method: The complet dermatological and allergological examinations were performed in 29 patients; 10 men, 19 women with the average age of 27.8 years, min. 17, max. 57 years; with the median SCORAD 24.2 points, s.d. 13.3 points. Wormwood, grass, dog dander, cat dander, dermatophagoides pharinae, dermatophagoides pteronyssinus and birch pollen were examined in diagnostic procedures. Skin prick tests, specific IgE were examined; the atopy patch tests were performed with aeroallergens for skin prick tests in concentration $1 \times$ skin prick tests. Results: Specific IgE and skin prick tests to one or more tested aeroallergens were positive altogether in 27 patients; atopy patch tests were positive only in one of these patients. Conclusion: For atopy patch testing with aeroallergens the concentration of $1 \times$ skin prick tests is low to confirme the eczematic reaction in patients suffering from allergy to inhallant allergens.

Key words: Atopic dermatitis; Atopy patch tests; Specific IgE; Skin prick tests

\section{Introduction}

Atopy patch test (APT) involves epicutaneous application of type I allergens known to elicit IgE - mediated reaction, followed by evaluation of eczematous skin reaction after 48 and $72 \mathrm{~h}$ (1). It represents a model of cellular immunity reaction and it is presumed to reflect delayedphase clinical reactions. According Tonzic (2), its value is supported by the fact that atopic dermatitis is the result of complex immune interactions and involves both Coombs and Gell reactions type IV and I. APT is considered as a useful diagnostic procedure in patients with atopic dermatitis allergic to inhalant allergens (house dust mite, pollen and animal dander) and in children with food allergy younger than 2 years. The sensitivity and specificity of the test greatly depend on the tested allergens and patient age (2).

The limitations of atopy patch tests include the lack of test standardization. After standardization, the APT may provide further diagnostic information in addition to the skin prick test and serum immunoglobulin $\mathrm{E}$ values and may be able to evaluate the actual clinical relevance of immunoglobulin E-mediated sensitizations for eczematous lesions (3). Various concentrations of allergens for APT are described in the literature, ranging from $1 \times$ skin prick test (SPT) $(10,000 \mathrm{AU} / \mathrm{ml})$ to $1,000 \times \mathrm{SPT}(4)$.

Aim of our study was the evaluation if the usage of $1 \times$ skin prick tests of aeroallergens $(=100 \mathrm{IR} / \mathrm{ml})$ is a convenient method for atopy patch testing. These tests were performed in patients suffering from atopic dermatitis in the age 14 years and older.

\section{Methods \\ Patients}

29 patients over 14 years of age with atopic dermatitis (the diagnosis was made according to the the Hanifin-Rajka criteria (5)) were examined at the outpatient department of Department of Dermatology and Venereology, Faculty Hospital and Medical Faculty of Charles University, Hradec Králové, Czech Republic, from September 2010 to May 2012.

Complete dermatological and allergological examination were performed in all included patients (including the examinations for asthma bronchiale with spirometry). The occurence of rhinoconjunctivitis was evaluated.

\section{Scoring of atopic dermatitis}

Severity of eczema was scored in agreement with SCORAD score, with assessment of topography items (affected skin area), intensity criteria (extent of erythema, oedema, crusts, excoriations, lichenification, xerosis), and subjective parameters (extent of itch and loss of sleep). Mild form to 20 points, moderate 21 to 50 points, over 50 points severe form of atopic dermatitis. 


\section{Tested allergens}

Wormwood, grass pollen, dog dander, cat dander, House dust mites - Dermatophagoides pharinae, Dermatophagoides pteronyssinus, birch pollen were used in testing procedures. After discontinuation of antihistamines and topical steroids for at least 5 days and systemic steroids and UV therapy at least 2 months, the skin prick tests, the atopy patch tests were performed. Specifig IgE was examined.

\section{Skin prick test}

Commercial extracts Alyostal (Stallergens, France) were used for skin prick tests (SPT).

SPTs were placed on the volar side of the forearm according to the extent of atopic dermatitis. SPTs were carried out by a standardized method using lancets with a $1 \mathrm{~mm}$ tip. The results were read after 15 minutes and were assessed by comparison with the wheal induced by histamine $(10 \mathrm{mg} / \mathrm{ml})$ and negative control. A wheal with a diameter greater than $3 \mathrm{~mm}$ in comparison with negative control was scored as positive.

\section{Specific IgE}

The serum level of the specific IgE to the tested aeroallergens has been measured with the method of CAP (system FEIA - Pharmacia Diagnostics, Uppsala, Sweden). The level of specific IgE higher than $0.35 \mathrm{U} / \mathrm{ml}$ was assessed as positive.

\section{Atopy patch tests}

Atopy patch tests were performed on non-lesional, non-abraded, untreated skin of the back during a remission.

A technique similar to conventional patch tests has been used by performing of atopy patch testing CURATEST F strip (Lohmann \& Rauscher International GmbH \& Co. KG D-56579, Rengsdorf, Germany) with $12 \mathrm{~mm}$ cup size. For atopy patch testing the concentrations of allergens $1 \times$ SPT was used - commercial extracts Alyostal (Stallergenes, France), $1 \mathrm{ml}$ of this allergen was administred to $12 \mathrm{~mm}$ cup size of patch testing. The reactions were evaluated in 48 and 72 hours after the first application of allergens.

Grading of positive APTs reactions was similar to the criteria used in conventional contact allergy patch testing with the modifications of the European task Force on Atopic Dermatitis (EFTAD) Consensus Meetings; i.e. + erythema, infiltration, ++ erythema, infiltration, papules (up to 3), +++ erythema, papules from 4 to many, ++++ erythema, many or spreading papules and vesicules. Test application and reading was performed by an investigator with no knowledge of the patient's history. Only reactions from + (erythema, infiltration) onwards were designated positive (6).

\section{Results}

\section{Patients}

Altogether 29 persons suffering from atopic dermatitis were included in the study: 10 men, 19 women with the average age of 27.8 years, min. 17 , max. 57 years; with the median SCORAD 24.17 points, s.d. 13.3 points.

\section{Personal history}

Rhinoconjunctivitis was recorded in 21 patients.

\section{Spirometry examination}

Asthma bronchiale was recorded in 12 patients.

\section{Specific IgE}

Specific IgE to tested aeroallergens were recorded in 16 patients (to birch in 2 patients, to grass in 7 patients, to wormwood in 4 patients, to cat or dog dander in 6 patients, and to dermatophagoides farinae or pteronyssinus in 9 patients) (table 1).

\section{Skin prick tests}

Positive results in skin prick tests to tested aeroallergens were recorded in 25 patients (to birch in 8 patients, to grass in 17 patients, to wormwood in 2 patients, to cat or dog dander in 5 patients, and to dermatophagoides farinae or pteronyssinus in 11 patients) (table 1).

\section{Atopy patch tests}

Atopy patch test were recorded as positive in 1 patient to wormwood, grass and dermatophagoides farinae (table 1, patient No 23), evaluated as ++. The positive results in skin prick tests were recorded to dermatophagoides farinae, grass and cat dander, in SIgE to grass and dermatophagoides farinae (table 1).

\section{Discussion}

The first experimental study on patch test with aeroallergens was published in 1937 by Rostenberg and Sulzberger, and in 1982 by Mitchell $(7,8)$ and various APT techniques have been described in the literature. In order to enhance the penetration of the allergen into the skin, skin abrasion, tape - stripping and sodium lauryl sulfate application were used (4). Today, APT is performed on nonlesional, untreated skin in remission (4). The European Task Force on Atopic Dermatitis (EFTAD) has developed a standardized APT technique. It consists of purified allergen preparation in petrolatum, applied in $12 \mathrm{~mm}$ diameter Finn chambers mounted on Scanpor tape to non-irritated, 
Tab. 1: Results of examination in 29 patients

\begin{tabular}{|c|c|c|c|c|c|c|c|}
\hline Patient, sex, age & Specific IgE & Skin prick test & $\begin{array}{c}\text { Atopy patch } \\
\text { test }\end{array}$ & $\begin{array}{l}\text { SCORAD } \\
\text { (points) }\end{array}$ & Total IgE IU/ml & $\mathrm{AB}$ & $\mathrm{RC}$ \\
\hline $1, \mathrm{~W}, 20$ & $\mathrm{D}, \mathrm{G}, \mathrm{CD}$ & - & - & 15 & 1224 & - & + \\
\hline $2, \mathrm{M}, 20$ & W, CD & $\mathrm{D}, \mathrm{W}$ & - & 30 & 608 & + & + \\
\hline $3, \mathrm{~W}, 27$ & $\mathrm{~B}, \mathrm{~W}$ & $\mathrm{D}, \mathrm{CD}, \mathrm{G}$ & - & 20 & 748 & - & + \\
\hline $4, M, 28$ & G & $\mathrm{D}$ & & 26 & 1071 & + & + \\
\hline $5, W, 15$ & $\mathrm{CD}$ & G & - & 32 & 200 & - & + \\
\hline $6, W, 39$ & $\mathrm{D}, \mathrm{CD}, \mathrm{W}$ & $\mathrm{G}$ & - & 32 & 2475 & + & + \\
\hline $7, \mathrm{~W}, 23$ & D. & G & - & 31 & 74 & - & - \\
\hline $8, W, 24$ & G & $\mathrm{G}, \mathrm{CD}$ & - & 27 & 86 & - & - \\
\hline $9, \mathrm{M}, 38$ & - & $\mathrm{D}, \mathrm{B}, \mathrm{CD}$ & - & 42 & 2331 & + & + \\
\hline $10, M, 38$ & $\mathrm{G}$ & $\mathrm{B}, \mathrm{G}$ & - & 20 & 89 & - & + \\
\hline $11, \mathrm{~W}, 26$ & $\mathrm{D}, \mathrm{G}, \mathrm{CD}$ & $\mathrm{G}, \mathrm{D}, \mathrm{B}$ & - & 35 & 335 & + & + \\
\hline $12, \mathrm{~W}, 26$ & $\mathrm{D}, \mathrm{G}$ & - & - & 31 & 632 & + & + \\
\hline $13, \mathrm{M}, 20$ & - & - & - & 32 & 4473 & + & + \\
\hline $14, \mathrm{M}, 21$ & - & $\mathrm{D}, \mathrm{CD}, \mathrm{G}$ & - & 18 & 181 & + & + \\
\hline $15, \mathrm{~W}, 21$ & - & $\mathrm{G}, \mathrm{B}$ & - & 22 & 1864 & - & + \\
\hline $16, M, 26$ & - & G & - & 19 & 547 & - & - \\
\hline $17, \mathrm{~W}, 30$ & - & $\mathrm{G}, \mathrm{B}$ & - & 28 & 25 & - & - \\
\hline $18, \mathrm{~W}, 57$ & - & G, D & - & 15 & 100 & + & + \\
\hline $19, \mathrm{~W}, 19$ & $\mathrm{~W}, \mathrm{CD}, \mathrm{D}$ & $\mathrm{G}, \mathrm{B}$ & - & 12 & 53 & - & - \\
\hline $20, W, 41$ & - & - & - & 12 & 120 & - & - \\
\hline $21, W, 38$ & - & $\mathrm{CD}$ & - & 19 & 23 & + & + \\
\hline $22, M, 19$ & - & $\mathrm{D}, \mathrm{G}$ & - & 25 & 4022 & - & + \\
\hline $23, \mathrm{M}, 17$ & $\mathrm{D}, \mathrm{G}$ & $\mathrm{D}, \mathrm{G}, \mathrm{CD}$ & $\mathrm{W}, \mathrm{G}, \mathrm{D}++$ & 28 & 5000 & + & + \\
\hline 24, M, 19 & - & $\mathrm{D}, \mathrm{W}$ & - & 29 & 768 & - & + \\
\hline $25, W, 25$ & - & G & - & 10 & 9 & - & + \\
\hline $26, \mathrm{~W}, 30$ & - & $\mathrm{B}$ & - & 11 & 527 & - & - \\
\hline $27, \mathrm{~W}, 39$ & D & $\mathrm{G}, \mathrm{D}$ & - & 18 & 163 & - & + \\
\hline $28, W, 43$ & G & G & - & 32 & 822 & - & - \\
\hline $29, \mathrm{~W}, 20$ & $\mathrm{D}, \mathrm{B}$ & $\mathrm{G}, \mathrm{B}$ & - & 30 & 1055 & + & + \\
\hline
\end{tabular}

W: wormwood; G: grass; CD: dog, cat dander; D: Dermatophagoides pharinae, Dermatophagoides pteronyssinus; B: birch; AB: asthma bronchiale + yes, - no; RC: rhinoconjunctivitis + yes, - no 
non-abraded, or tape-stripped skin on the upper back (8). The test is read after 48 hours and 72 hours and the reading key is the appearance of erythema, and the number and distribution pattern of the papules. Usage of aeroallergens concentration over 5,000 PNU (protein nitrogen units/g in petrolatum allows for testing on clinically uninvolved skin without potentially iritating tape-stripping (9).

Various concentrations of allergens are described in the literature, ranging from $1 \mathrm{x}$ SPT $(10,000 \mathrm{AU} / \mathrm{ml})$ to $1,000 \times$ SPT (4). Van Voorst Vader et al.conclude that the optimal allergen concentration should be $500 \times$ SPT with exposure time of $48 \mathrm{~h}$ (10). Langeveld-Wildschut et al. conclude that concentration should be equal to $1 \times$ SPT and according to their results increasing the allergen concentration to up $10 \times$ SPT did not significantly influence the number of positive results (11).In their study, APTs were performed in 84 patients with atopic dermatitis, 30 control patients with atopic disease, and 85 healthy volunteers, with house dust mite and grass pollen allergens in concentrations of 100 , 1,000, 10,000, and 100,000 allergenic units $/ \mathrm{ml}$.

The authors from Poland also studied the impact of allergen concentration and found that $0.1 \times$ SPT was too low, while $10 \times$ SPT concentration had significantly more positive reactions than $1 \times \mathrm{SPT}(12)$.

When biopsy is performed from allergen-induced eczematous APT site, allergen specific T cells are cloned (13)). The TH2 cytokine pattern is initially present and after $48 \mathrm{~h} \mathrm{TH} 1$ pattern is predominant (13). An early influx of inflammatory dendritic epidermal cells into lesional skin has been demonstrated (14). When allergen is captured by IgE molecules, it binds to IgE receptor on Langerhans cells. Antigen presentation results in specific T cell reaction which is responsible for eczematous reaction observed clinically (14). T cells are responsible for the reaction occuring in lesional skin in atopic dermatitis and also in the skin in APT, and macroscopic and microscopic similarities indicate that APT is valid model for inflammation found in atopic dermatitis (15).

According to our results in specific IgE and in skin prick test, the allergy to aeroallergens is common in patients suffering from atopic dermatitis; 12 patients of our study suffer from asthma bronchiale and 21 patients from rhinoconjunctivitis. The positive result in atopy patch test was recorded only in one patient. This patient suffers from moderate form of atopic dermatitis, from allergy to aeroallergens according to the result in SIgE and SPT, suffers from asthma bronchiale and rhinoconjunctivitis; his level of total $\mathrm{IgE}$ is $5,000 \mathrm{IU} / \mathrm{ml}$, this level is the highest in comparison with the results of other patients.

Literature data indicate that positive APT reactions can occur in $15-90 \%$ of atopic eczema patients, depending on the methodology used in testing $(12,16)$. Healthy individuals as well as patients with respiratory atopy without a history of eczema have negative APT or react to house dust with lower frequency and intensity compared with atopic patients (12).
Ronchetti et al. found positive APT with food in 4-11\% and with aeroalleregens in $4-30 \%$ of an unselected children population, depending on allergen tested (17), and these results are in conflict to other study results $(4,18)$.

For our atopy patch testing the concentrations of allergens $1 \times$ SPT was used from commercial extracts Alyostal (Stallergenes, France). This company makes use IR units in skin prick tests. The definition is that it is a measure of allergenic efficacy; it is extract of allergens with the content of $100 \mathrm{IR}$, which provokes in skin prick test with the use of lancet Stallerpoint a wheal about the size $7 \mathrm{~mm}$ in 30 patients with sensibilisation to this allergen. The other company producing skin prick tests ALK Abelló has units of allergens in HEP (histamin equivalent prick) and Sevapharma makes use of PNU/g (Protein nitrogen units/g). That is why it is difficult to identify the solutions in skin prick tests with high concentration of allergens, because each company represented on the market (Sevapharma, Stallergenes, ALK Abelló) has chosen its own allergen standardization with its own unit of measure. The direct conversion from one unit to another is not possible. What is missing is the 'gold standard' upon which the various 'currencies' orient themselves and which allows clear comparability. We can conclude, that the concentration of $1 \times$ skin prick tests of Stallergenes is not right for atopy patch testing.

The European APT model used with standardization of allergen concentration and vehicle may provide an important diagnostic tool to select patients for avoidance and for procedures of allergen-specific immunotherapy, but the clinical relevance of positive APT reactions awaits standardized provocation and avoidance testing (3).

\section{Conclusion}

The concentration of aeroallergens of $1 \times$ skin prick tests (extracts Alyostal, Stallergenes, France) is too low to confirme the eczematic reaction in patients suffering from allergy to inhallant allergens in atopy patch testing.

\section{References}

1. Turjanmaa K, Darsow U, Niggeman B, et al. Position paper, EAACI/GA2LEN: Present status of the atopy patch test, Allergy, 2006; 61: 1377-84.

2. Toncic R, Lipozencic J. Atopy patch test - when it is useful? Acta Med Croatia, 2011; 65 (2): 97-106.

3. Lipozenic J, Wolf R. The diagnostic value of atopy patch testing and prick testing in atopic dermatitis: facts and controversies. Clin Dermatol, 2010; 28 (1): 38-44

4. Darsow U, Vieluf D, Ring J. Atopy patch test with different vehicles and allergen concentrations - an approach to standardization. J Allergy Clin Immunol, 1995; 95: 677-84.

5. Hanifin J, Rajka G. Diagnostic features of atopic dermatitis. Acta Derm Venereol 1980; Suppl 92: 44-47.

6. Darsow U, Laifaoui J, Kerschenlohr K, et al. The prevalence of positive reactions in the atopy patch test with aeroallergen and food allergens in subjects with atopic eczema: a European multicenter study. Allergy, 2004; 59 (12): 1318-25.

7. Rostenberg A, Sulzberger M. Some results of atopy patch tests. Arch Dermatol, 1937; 35: 433-54.

8. Mitchell E, Chapman M, Pope F, et al. Basophils in allergen - induced patch test sites in atopic dermatitis. Lancet, 1982; 1: 127-30.

9. Kerschenlohr K, Darsow U, Burgdorf WH, Ring J, Wollenberg A. Lessons from atopy patch testing in atopic dermatitis. Current Allergy and Asthma Reports, 2004; 4: 285-89. 
10. van Voorst Vader P, Lier J, Woest T, Coenraads P, Nater J. Patch test with house dust mite antigens in atopic dermatitis patients: methodological problems. Acta Derm Venereol, 1991; 71: 301-5.

11. Langeveld-Wildschut E, van Marion A, Thepen T, Mudde G, Bruijnzeel P. Evaluation of variables influencing the outcome of the atopy patch test. J Allergy Clin Immunol, 1995; 96: 66-73.

12. Czarnecka-Operacz M, Bator-Wegner M, Silny W. Atopy patch test reaction to airborne allergens. Acta Dermatovenerol Croat, 2005; 13: 3-16.

13. van Reijsen FC, Bruijnzeel-Koomen CA, Kalthoff FS, et al. Skin-derived aeroallergen-specific T-cell clones of $\mathrm{Th} 2$ phenotype in patients with atopic dermatitis. J Allergy Clin Immunol, 1992; 90: 184-93.

14. Sager N, Feldmann A, Schilling G, Kreitsch P, Neumann C. House-dust mite-specific $\mathrm{T}$ cells in the skin of subjects with atopic dermatitis: frequency and lymphokine profile in the allergen patch test. J Allergy Clin Immunol, 1992; 89: $801-10$

15. Langeveld-Wildschut E, Bruinzeel $P$, et al. Clinical and immunologic variables in skin of patients with atopic eczema and either positive or negative atopy patch test reactions. J Allergy Clin Immunol, 2000; 105: 1008-16.

16. Langeland T, Braathen LB, Borch M. Studies of atopic patch test. Acta Derm Venereol Suppl (Stockh), 1989; 144: 105-9.

17. Ronchetti R, Jesenak M, Trubacova D, Pohanka V, Villa M. Epidemiology of atopy patch tests with food and inhalant allergens in an unselected population of children. Pediatr Allergy Immunol, 2008; 19: 599-604.

18. Ingordo V, Dalle Nogare R. Is the atopy patch test with house dust mites specific for atopic dermatitis? Dermatology, 2004; 209: 276-283.

Received: $13 / 10 / 2012$

Accepted in revised form: 16/01/2013

\section{Corresponding author:}

Jarmila Čelakovská, MD, PhD. Department of Dermatology and Venereology, University Hospital, Sokolská 581, 50005 Hradec Králové, Czech Republic; e-mail: jarmila.celakovska.@seznam.cz 